\title{
PLANEJAMENTO ESTRATÉGICO E O PROCESSO DE SUSTENTABILIDADE PARA OS DESAFIOS ENFRENTADOS NO AGRONEGÓCIO
}

Maurício Dias Marques ${ }^{1}$

Lucas Seolin Dias ${ }^{2}$

\section{Resumo:}

Diante das incertezas econômicas, sociais e ambientais do cenário atual globalizado, o planejamento estratégico em qualquer organização torna-se fundamental, e na área do agronegócio não é diferente. Este trabalho visa apresentar as vantagens de um planejamento estratégico para o processo de sustentabilidade na área do agronegócio. Buscou-se, por meio de um levantamento teórico bibliográfico, analisar e compreender os aspectos gerais sobre o assunto. $\mathrm{E}$ evidenciou-se que o planejamento estratégico proporciona maior segurança para a tomada de decisões ante as projeções de incertezas futuras, sendo importante sua implantação para o processo de sustentabilidade também no agronegócio. Estudos mais aprofundados são sugeridos para verificar a realidade sobre a implantação desse planejamento.

Palavras-chave: planejamento estratégico, sustentabilidade, agronegócio.

\section{STRATEGIC PLANNING AND THE PROCESS OF SUSTAINABILITY FOR THE CHALLENGES FACED IN AGRIBUSINESS}

\section{ABSTRACT:}

\footnotetext{
${ }^{1}$ Mestrando em Agronegócios e Desenvolvimento, UNESP-Tupã, e-mail: mdmarques1985@gmail.com ${ }^{2}$ Mestrando em Administração, UEL-Londrina, e-mail: lucas_seolin@yahoo.com.br
} 
In the face of economic, social and environmental uncertainties of the globalized present scenario, strategic planning in any organization it is essential, and in the agribusiness area is no different. This paper presents the advantages of a strategic planning process for sustainability in the agribusiness area. It is sought, through a bibliographic theoretical research, analyze and understand the general aspects about it. And it became clear that strategic planning provides greater security for decision making at the projections of future uncertainties, and its implementation is very important for the process of sustainability also in agribusiness. Further studies are suggested to a reality check on the implementation of this planning.

Keywords: strategic planning, sustainability, agribusiness.

\section{PLANIFICACIÓN ESTRATÉGICA Y EL PROCESO DE SOSTENIBILIDAD DE LOS RETOS QUE ENFRENTAN EN AGRONEGOCIOS}

\section{RESUMEN:}

A la vista de las incertidumbres económicas, sociales y ambientales del actual escenario globalizado, la planificación estratégica en cualquier organización es esencial, y en el área de la agroindustria no es diferente. Este artículo presenta las ventajas de un proceso de planificación estratégica para la sostenibilidad en el área de la agroindustria. Se pretende, a través de una investigación teórica bibliográfica, analizar y comprender los aspectos generales al respecto. $Y$ se hizo evidente que la planificación estratégica proporciona una mayor seguridad para la toma de decisiones en las proyecciones de las incertidumbres del futuro y su aplicación es muy importante para el proceso de sostenibilidad también en la agroindustria. Se sugiere otros estudios para una revisión de la realidad sobre la aplicación de esta planificación.

Palabras clave: planificación estratégica, la sostenibilidad, la agroindustria. 


\section{INTRODUÇÃO}

Planejar qualquer atividade é esquematizar base de sustentação e projetar antevisão de acontecimentos futuros. O planejamento estratégico consiste em visão futura, distante, mormente sob influências não controláveis internamente nas organizações, mas dependentes de fatores externos. O agronegócio, tal qual qualquer outro setor de empreendimento humano, sente a necessidade de um planejamento com visão estratégica para manutenção e projeção no atual ambiente globalizado. Ainda mais, em um cenário afetado por incertezas e insegurança. Segundo Bauman (1998) o mundo, tal como se apresenta, está se preparando para uma vida de incerteza contínua; para Hall (2006) a sociedade se encontra num momento de crise de identidade, pelo qual os sujeitos são caracterizados por não possuírem identidades fixas ou permanentes, ademais, conforme o autor, são sociedades marcadas por mudança constante e permanente. E diante dessa realidade, os reclamos da sustentabilidade tem ganhado cada vez mais destaque. Sustentabilidade que, por sua vez, passou a ser um conceito muito propagado nos últimos anos, principalmente quando se refere à conservação e preservação do meio ambiente, e cuja tendência é ganhar maior visibilidade e importância.

Este trabalho tem por objetivo apresentar uma visão ampla sobre o planejamento e a sustentabilidade aplicáveis ao agronegócio. Por que o planejamento estratégico tem sua importância de aplicação no agronegócio, diante da sustentabilidade? Por meio de uma pesquisa bibliográfica procurou-se analisar os principais aspectos que envolvem um planejamento estratégico, sua definição, utilidade, até as possibilidades de sua aplicação. Apresenta-se também uma conexão entre o planejamento estratégico e a sustentabilidade, dando maior ênfase à área do agronegócio, dada sua representativa importância econômica. $\mathrm{O}$ trabalho não tem a intenção de esgotar o assunto, mas alimentar a busca por mais pesquisas que envolve essa temática. 


\section{METODOLOGIA}

O método de pesquisa permite ao pesquisador orientar seu trabalho no sentido de alcançar seu objetivo de maneira planejada quanto às observações, experimentos e análise de resultados e de informações. Neste texto, de acordo com o objetivo proposto, o método utilizado para um estudo inicial, foi a realização de uma pesquisa bibliográfica analisando os aspectos gerais sobre planejamento e a sustentabilidade procurando estabelecer uma conexão com o agronegócio.

A pesquisa bibliográfica tem a finalidade de colocar o pesquisador em contato direto com tudo o que foi escrito, dito ou filmado sobre um determinado tema, propiciando o exame de um tema sob novo enfoque ou abordagem, permitindo-se chegar a novas conclusões (MARCONI; LAKATOS, 2010).

Conforme Gil (2014), a principal vantagem da pesquisa bibliográfica está no fato de permitir ao pesquisador a cobertura de uma gama muito mais ampla de fenômenos. E, Medeiros (2012), considera que a pesquisa bibliográfica significa o levantamento da bibliografia sobre o assunto que se deseja estudar, através de quatro etapas: identificação (levantamento do material bibliográfico); localização (de textos específicos); compilação (reunião do material desejado) e fichamento (transcrição dos dados, anotações).

Sendo assim, fez-se uma revisão de textos concernentes ao planejamento estratégico, agronegócio e sustentabilidade, e também ao planejamento e agronegócio ligado à sustentabilidade, tendo sido apanhadas ideias de autores, a partir de revistas, periódicos, teses e dissertações. Essa revisão bibliográfica possibilitou evidenciar vantagens do planejamento estratégico no processo de sustentabilidade no agronegócio, dando abertura para futuras pesquisas.

\section{IMPORTÂNCIA DO PLANEJAMENTO ESTRATÉGICO}

Qualquer empreendimento humano tem a competitividade como mola mestra para o sucesso. No momento atual, as empresas e o agronegócio, consideradas como organizações, operam num ambiente globalizado. 
Para Motta (1976), a organização, como sistema aberto, enfatiza a sua sensibilidade a pressões externas e a necessidade de resposta a essas pressões de forma efetiva. Concebida no passado como sistema fechado, seu crescimento e progresso era através do domínio e eficiência das funções organizacionais internas. Atualmente, há um novo quadro em que se coloca a natureza das transações ambiente-organização como fator de peso para a sobrevivência e desenvolvimento organizacionais. Ainda que pressões ambientais sempre existiram é nas organizações modernas que a transação ambiente-organização merece atenção especial.

Segundo Coral (2002), nesse ambiente altamente competitivo é preciso planejar o desenvolvimento futuro, não só para sobrevivência, mas para crescer, enfrentando os novos desafios. Adverte ainda:

Os modelos de planejamento estratégico existentes enfatizam principalmente as questões econômicas, relegando a segundo plano, as questões ecológicas e sociais, que devido ao cenário apresentado, precisam ser incorporadas na gestão estratégica das organizações. (CORAL, 2002, p. v-resumo)

Procurando compreender o que seja estratégia organizacional, interessante a seguinte concepção:

No contexto organizacional, a estratégia corresponde à capacidade de se trabalhar contínua e sistematicamente o ajustamento da organização às condições ambientais que se encontram em constante mudança, tendo sempre em mente a visão de futuro e a perpetuidade organizacional.

No significado em geral sobre "estratégia" observa-se que seu norte principal diz respeito a ser capaz de posicionar-se corretamente frente às situações principalmente quando se está diante de incertezas e turbulências do ambiente, seja ele no plano financeiro, seja no âmbito de suas atividades internas e processuais.(BARBOSA e BRONDANI, 2005, p. 109)

Ao realizar um planejamento estratégico, segundo Silva, Pereira e Sproesser (2011), há necessidade de analisar minuciosamente o setor nos últimos tempos, a situação interna da empresa e fazer projeções futuras, com vistas a obter preferência do seu público.

Ainda, segundo Silva, Pereira e Sproesser (2011), considerando-se as características da instabilidade do "agribusiness", não é fácil um planejamento estratégico que seja realmente eficaz, que leve a obtenção de vantagem competitiva. Inclua-se nessa vantagem 0 atendimento ao processo de 
sustentabilidade, pela observação dos três pilares característicos da sustentabilidade.

Desde o surgimento da administração científica de Taylor, o planejamento é considerado uma das principais funções administrativas. O planejamento destina-se a obtenção de maior eficiência e produtividade. A sobrevivência de qualquer organização, mormente nos dias atuais, inclusive àquelas vinculadas ao agronegócio, não prescinde do planejamento.

Segundo Barbosa e Brondani (2005), planejar implica na formulação sistemática de objetivos e ações alternativas, escolhendo-se a melhor ação. Também implica em reflexos de decisões presentes no futuro, sendo um processo de decisões recíprocas e independentes visando alcançar objetivos anteriormente estabelecidos.

Conforme Motta (1976), pode-se pensar na "capacidade da organização para perceber mudanças em valores ambientais desejáveis e transformá-los em objetivos organizacionais relevantes". E,

O planejamento organizacional não pode fundamentar-se na análise institucional das normas, regras e influências, presentes nas instituições do ambiente, mas, sim, nas possíveis variações futuras do impacto de diferentes valores e normas que incidirão sobre a organização. (MOTTA, 1976, p. 86)

De acordo com Fernandes (2002), o planejamento é realizado em três níveis:

Planejamento operacional: estabelece cronogramas, tarefas específicas e alvos mensuráveis, envolvendo gerentes de cada unidade. Pode ser mensal, semanal ou mesmo diário.

Planejamento tático: tem por objetivo o exame específico de determinadas áreas de resultado, como divisões, funções empresariais, etc. Desenvolve-se ainda em um nível organizacional inferior.

Planejamento estratégico: de responsabilidade dos níveis mais altos da empresa, com participação dos outros níveis, examina as questões principais da organização, considerando o ambiente externo e o interno, tendo então um horizonte de tempo longo. 
Motta (1976), já registrava que:

Enfim, o que se enfatiza modernamente é que existe uma responsabilidade gerencial de alto nível pelo futuro da organização; esta responsabilidade deve ser enfrentada pelos executivos, em termos de aumentar o seu conhecimento sobre fatores externos que afetam a sua empresa e estabelecer um senso de direção futura para seus negócios. Esse é um processo contínuo e sistemático de avaliação da organização e não um processo ocasional de dimensionar a organização e reavaliar os seus objetivos. (MOTTA, 1976, p. 90)

$\cdots$

Como se pode notar, o planejamento estratégico se volta para o alcance de resultados, através de um processo contínuo e sistemático de antecipar mudanças futuras, tirando vantagem das oportunidades que surgem, examinando os pontos fortes e fracos da organização, estabelecendo e corrigindo cursos de ação a longo prazo. (MOTTA, 1976, p. 92)

Para Barbosa e Brondani (2005), uma das ideias básicas do planejamento estratégico é a própria estratégia, ou melhor, para cada tipo de negócio a empresa tem que criar uma estratégia para alcançar os objetivos de longo prazo. Cada empresa deve escolher o que the seja melhor, tendo em vista a sua posição no mercado, os objetivos, as oportunidades e os recursos disponíveis.

No caso do agronegócio, tanto os grandes empreendimentos voltados à produção em larga escala com comercialização em nível mundial (as commodities), quanto o pequeno agente do agronegócio (um pequeno produtor de milho, por exemplo), têm condições de elaborar um plano estratégico, de acordo com a sua posição no mercado.

Muito sinteticamente, as quatro etapas na elaboração de um planejamento estratégico, resumidos por Silva, Pereira e Sproesser (2011), seriam:

a) definição da missão e dos objetivos da empresa: informa a todos quem é a organização e onde pretende chegar;

b) análise interna e externa do ambiente organizacional e avaliação: ferramenta que analisa as forças e fraquezas do ambiente interno (intraorganizacional) e as oportunidades e ameaças do ambiente externo (mercado).

c) alocação de recursos: investir os recursos da organização, sejam humanos, materiais, patrimoniais e financeiros, em setores onde a análise acima demonstrou maior viabilidade; 
d) adequação dos planos tácitos e operacionais para executar o planejamento proposto: parte-se para a elaboração dos planos de hierarquia inferior, o planejamento tácito e por fim o operacional.

Um planejamento estratégico eficiente, ao ser executado, leva ao sucesso empresarial, dando segurança para os gestores e demais funcionários, consequentemente trazendo ao empreendimento uma posição de destaque ou liderança.

Ainda, conforme Silva, Pereira e Sproesser (2011), há que se trabalhar ou pensar alguns pontos chave:

a) infraestrutura da empresa: a estrutura deve ser ideal para o tamanho da empresa. Ex: quem tem apenas dez hectares não necessitará de grandes equipamentos, que ficarão ociosos. Ex: um avião pulverizador.

b) gerência de recursos humanos: a gestão de pessoal possui custos enormes em nosso país. No "site" Guia do Empresário, encontra-se uma análise de que o custo da mão de obra chega a $114,73 \%$ sobre a remuneração bruta.

c) desenvolvimento de tecnologia: inovações como sementes transgênicas mais resistentes às pragas, criações geneticamente modificadas, resultado de pesquisas da Empresa Brasileira de Pesquisa Agropecuária - Embrapa.

d) aquisição: é preciso verificar a competição de preços. Além disso, cuidados são necessários. Por exemplo, optando por uma semente diferenciada (não modificada geneticamente), todo o processo (prensagem, armazenagem, transporte) deve ser limpo, sem a presença de grãos com qualquer grau de transgenia.

e) logística interna: transporte de sementes, maquinários, implementos, ração, enfim, dos insumos para "dentro da porteira". A preferência pela imprópria malha rodoviária encarece o custo de transporte.

f) operações: a atividade de transformação dos insumos em produtos finais. $O$ custo e manejo dependerá do mercado a atuar (commodity, orgânico, etc.).

g) logística externa: escoamento da produção. A maior eficiência brasileira depende da capacidade de reestruturar a malha ferroviária e desenvolver, onde possível, as hidrovias. 
h) marketing e vendas: como, no Brasil, a maioria dos produtos do agronegócio são comoditizados, pouco se foca em qualidade e diferenciação, mantendose atenção ao preço.

Segundo Motta (1976, p. 96), o planejamento estratégico tem a função de procurar servir de guia das organizações para "o crescimento e o desenvolvimento planejados, para assumir a direção socialmente correta do fortalecimento econômico e do tamanho ótimo em cada etapa de crescimento."

O planejamento estratégico pode ser considerado como requisito básico de gestão para o desenvolvimento sustentável e a sustentabilidade. Conforme Coral (2002), o desenvolvimento sustentável ainda não tem seus conceitos fundamentados no nível estratégico da indústria (e aqui poderia acrescentar-se "do agronegócio"), não recebendo a priorização devida. As ações para redução da geração de resíduos e alternativas para tratamento e disposição final deste, geralmente são estabelecidas por pressões externas (exigências legais ou de mercado). Assim, há necessidade de mecanismos que auxiliem as organização na análise estratégica e no planejamento do processo de sustentabilidade. Haveria, também, necessidade de implementação de estratégias ambientais proativas, já que o mercado consumidor está cada vez mais consciente na busca de produtos que não agridam o meio ambiente, dispondo-se a pagar mais por isso.

\section{Ainda, para Coral:}

A inclusão dos conceitos de sustentabilidade no planejamento estratégico será de suma importância para iniciar uma mudança nos paradigmas de gestão, possibilitando maior interação e cooperação tanto internamente, como com outras organizações parceiras e a própria comunidade onde a empresa está inserida, promovendo o desenvolvimento local e, consequentemente, do país. (CORAL, 2002, p. 6)

Focalizando o agronegócio do ponto de vista da sustentabilidade, deve-se pensar num planejamento estratégico que visualize o uso racional da terra, dos recursos naturais, que desperte interesse do consumidor e quaisquer outros públicos que tenham ligação com a produção rural em torno da preservação do meio ambiente. Isso implica em sustentabilidade.

Segundo Mazza et al (2014), na tendência atual, a gestão ambiental é uma alternativa que vem ao encontro dos interesses socioeconômicos da humanidade, cada vez mais presente no segmento empresarial, passando a ser vista pelas 
organizações mais como geradora de lucros do que de custos, além de ligar-se diretamente à sustentabilidade. Minimizando impactos ambientais com redução de custos estar-se-á proporcionando a preservação e recuperação da qualidade ambiental para as atuais e futuras gerações.

Ainda, Mazza et al (2014), relembra as palavras de Nascimento (2008) mencionando que a organização que incorpora as questões ambientais ao seu planejamento estratégico está implantando a gestão socioambiental estratégica, sendo esse o caminho para as organizações que decidirem assumir a responsabilidade social, tornando seus processos produtivos mais sustentáveis e contribuindo para a construção do desenvolvimento global.

\section{PLANEJAMENTO ESTRATÉGICO E A SUSTENTABILIDADE NO AGRONEGÓCIO}

A busca por uma agricultura sustentável traz importância ao planejamento. As discussões sobre o desenvolvimento sustentável do planeta tornam-se cada vez mais recorrentes nos diferentes contextos sociais e áreas do conhecimento. É claro que os empreendimentos do agronegócio não podem furtar-se a essa temática.

Mazza et al (2014), identificam que vários autores conceituam sustentabilidade procurando encontrar uma forma sistemática para operacionalizá-la nas organizações. E essa operacionalização já teve diversas conotações, com vários modelos de destaque, tanto no meio acadêmico, quanto empresarial. Um dos principais modelos, com um padrão mínimo de operacionalização é o denominado Triple Botton Line - TBL, conhecido como Tripé da Sustentabilidade de Elkington (2012), que abarca três dimensões (econômica, social e ambiental), as quais devem estar integradas, de maneira a aproveitar os recursos de forma eficaz. Para contribuir para a sustentabilidade, as organizações devem modificar seus processos produtivos, com novos sistemas de produção, sem impactos negativos ao meio ambiente, ao mesmo tempo que devem contribuir para a recuperação de áreas degradadas e oferecer produtos e serviços que possam contribuir para a melhoria da performance ambiental dos consumidores.

A gestão ambiental está assumindo uma maior importância frente à dimensão ambiental como um dos pilares do desenvolvimento sustentável, sendo 
assim é de suma importância para as empresas incorporarem a questão ambiental em suas estratégias. Para Mazza et al (2014), a implementação de práticas ambientais corretas na empresa, além de atender à legislação, proporciona também benefícios à imagem da empresa. Desse modo, haverá benefícios para os dois lados, a sociedade em geral e a própria organização.

Cantelle et al (2013, p. 173), afirmam que "setores como a agricultura podem contribuir para o desenvolvimento econômico sem prejudicar e alterar o meio ambiente ou podem, dentro dos critérios de sustentabilidade, comprometer a sobrevivência humana."

No que concerne ao conceito e "imagem" de uma determinada organização "as empresas que mantêm investimentos em sustentabilidade de forma estratégica e com visão de longo prazo podem beneficiar-se de uma vantagem competitiva de blindagem em relação aos efeitos da crise." (CLARO e CLARO, 2014, p. 292).

Para Oliveira e Camargo (2014), simultaneamente à consolidação do modelo de produção projetado pela Revolução Verde, no final da década de 1980, foi criado o conceito de sustentabilidade: "desenvolvimento que supre as necessidades da geração presente sem comprometer a capacidade de as futuras gerações suprirem suas próprias necessidades" (WCED, 1987). Esse conceito se apoia em três pilares: econômico, social, e ambiental. A falta de um desses pilares implica em desenvolvimento não sustentável, já que essas estão interligados e são interdependentes.

Coral (2002) coloca que:

O conceito de Desenvolvimento Sustentável originou-se do Ecodesenvolvimento, criado por Maurice Strong, secretário geral da Estocolmo 72. O Ecodesenvolviemnto tinha cinco princípios de sustentabilidade (social, econômico, ecológico, espacial/geográfico e cultural). O conceito foi fundamentado e amplamente divulgado através do relatório "Nosso Futuro Comum", elaborado pela Comissão Mundial de Desenvolviemnto e Meio Ambiente das Nações Unidas, em 1987. Mas conhecido como o relatório Brundtland, define desenvolvimento sustentável como "o desenvolvimento que atende às necessidades do presente, sem comprometer as necessidades das gerações futuras" (WCED, 1987). (CORAL, 2002, p. 16)

Não existe a possibilidade de oferecer a todos os habitantes do planeta os mesmos padrões de consumo dos países desenvolvidos. Por isso, 0 alcance da sustentabilidade das nações exigirá profundas mudanças estruturais, culturais, além de uma alta inovação tecnológica em todos os níveis, do individual ao internacional, ou seja, uma mudança nos 
paradigmas que hoje regem os modelos econômicos e sociais. (CORAL, 2002, p. 17)

Conforme registra Coral (2002), no Brasil, as políticas para o desenvolvimento sustentável vêm sendo elaboradas através da construção da Agenda 21 nacional e das Agendas 21 locais, de forma participativa, procurando unir os atores para estabelecer as prioridades regionais. A Agenda 21 objetiva definir uma estratégia de desenvolvimento sustentável para o país, por meio de articulação e parceria entre o governo e a sociedade, com uma abordagem multisetorial da realidade brasileira.

Constitui-se de um processo de planejamento estratégico quem visa atingir o desenvolvimento sustentável. Sendo este um instrumento que pode ser utilizado por qualquer instância de governo no âmbito nacional, estadual ou municipal e mesmo em empresas e instituições, por diferentes atores sociais em um planejamento fundamentado no marco da sustentabilidade, ou seja, que aborde os aspectos econômicos, sociais e ambientais (CORAL, 2002, p. 22)

Sustentabilidade, portanto, deve ser entendida genericamente envolvendo três campos: ambiental, social e econômico. No modelo single bottom line, as empresas mantêm os investimentos que sabem fazer melhor e acabam beneficiadas por ganhos de eficiência gerados pelas dimensões sociais e ambientais. Pode-se considerar que o desenvolvimento de produtos e serviços e a consequente geração de lucro pelas empresas (campo econômico) já são capacidades e habilidades das mesmas. Cabe agora, o esforço para ampliar a eficiência na gestão que envolve as outras duas dimensões.

Oliveira e Camargo (2014, p. 782), em referência às declarações de Delgado (2001), proclamam que:

\footnotetext{
O desenvolvimento rural sustentável enfatiza a necessidade de manutenção dos recursos naturais e produtividade agrícola, exercendo assim mínimos impactos sobre o meio ambiente, além de racionalizar a utilização de insumos químicos, e de satisfazer as necessidades alimentícias e sociais das famílias associadas a este tipo de trabalho. Assim, além da exploração econômica, os sistemas devem preconizar também a reprodução ecológica e social.
}

Sustentabilidade estratégica, aqui enfocada, propõe investimentos em projetos e ações sociais e ambientais relacionados com 0 negócio do empreendimento, com vistas a um impacto de longo prazo. 
Segundo Motta (1976), o principal e fundamental problema abordado no planejamento estratégico é a decisão sob incerteza. Decisões estratégicas certamente envolvem maior grau de incerteza que outras decisões, pois transcendem os limites da organização. São decisões que envolvem longo prazo e que focalizam fatores externos. O planejamento estratégico para diminuir a incerteza e o risco dessas decisões é questão de racionalidade. O administrador procurará agir em condições de segurança, evitando incertezas com decisões programadas, mantendo certa segurança psicológica. Sabendo-se que se está diante do futuro desconhecido, incerto e imprevisto, reprime-se essa incerteza com a presunção implícita de que o estado atual dos fatores deve perdurar no futuro. Assim, o planejamento estratégico está afeto a um processo contínuo de buscar conhecimento e informações externas, informações vitais para efetuar "análise de risco", trabalhar com fatores de probabilidade, com alternativas.

Claro e Claro (2014) propõe quatro estratégias de sustentabilidade: estratégia de redução da poluição, estratégia de gerenciamento do produto, estratégia de tecnologia limpa e estratégia de visão sustentável.

Os problemas ambientais e sociais precisam ser encarados de forma estratégica para gerar valiosas oportunidades de negócio. Além disso, a sustentabilidade estratégica também visa minimizar custos e riscos provenientes de consumo, poluição e geração de lixo, pois relaciona-se com as mudanças no que tange ao uso de recursos (quantidade e tipos), o que pode levar a maior eficiência no processo. (CLARO; CLARO, 2014, p. 296)

Para Cantelle et al (2013), a preocupação com o meio ambiente, compreendendo a continuidade dos recursos naturais renováveis e o uso de formas alternativas de consumo "tornaram-se uma área de interesse das empresas que querem garantir seu desenvolvimento e sobrevivência no mercado nacional e internacional."

É ainda Cantelle et al que expressam:

Empresas da atividade agrícola, que são aquelas envolvidas na produção, processamento, armazenamento e distribuição de commodities da agricultura, incluindo também o fornecimento de insumos, como sementes, fertilizantes e pesticidas, têm como maior desafio garantir e aumentar a produtividade e, ao mesmo tempo, conservar os recursos naturais, bens de interesse comum, mantendo um alicerce saudável para todos aqueles que dependem da atividade agrícola como subsistência. Uma das maneiras para se alcançar essas metas encontra-se em três elementos da agricultura sustentável: rentabilidade, proteção ambiental e justiça social. (CANTELLE et al, 2013, p. 177) 
Num ambiente globalizado e competitivo, quem não atender às normas do mecanismo competitivo e das exigências dos consumidores, encontrará barreiras. $E$, o mercado encontra-se cada vez mais seletivo em busca de empreendimentos que levam em consideração as práticas ambientais com a preocupação com o meio ambiente.

De acordo com Pereira Junior et al (2013), vários estudos mostram que a imagem do impacto ambiental das empresas está relacionada com a decisão de compra dos consumidores. Coloca também que, de acordo com Churchill e Peter (2000), 93\% dos consumidores analisar o impacto ambiental que um produto pode causar antes de comprá-los. E conclui que essa tomada de consciência dos consumidores atualmente pode ser observada no mercado brasileiro. Além das penalidades governamentais, a punição por destruir o meio ambiente parte dos consumidores que param de consumir produtos de empresas que não são ambientalmente responsáveis.

Cantelle et. al (2014, p. 185), trazem algumas questões para reflexão:

a) Qual o papel do comércio agrícola na harmonização entre ambiente e economia?

b) Por que a política ambiental brasileira, através de seus instrumentos, não prioriza a adoção de sistemas produtivos menos agressivos?

c) Como as empresas rurais podem trabalhar visando à manutenção dos recursos ambientais e, consequentemente, produtivos?

d) Como o conceito de economia verde, proposto pelo PNUMA, será abordado pelas políticas setoriais?

É certo que, dentro dos princípios da sustentabilidade, notadamente as questões sociais, econômicas e ambientais estão interligadas. Ao tratar do assunto, não se deve separar questões sociais das ambientais, por exemplo. Assim,

Quando uma organização é ecologicamente sustentável, ela também estará atuando de forma socialmente responsável, de forma a atender os interesses de todos os stakeholders que afetam ou são afetados por suas atividades. As organizações ecologicamente sustentáveis estarão voltadas para a implementação de estratégias ambientais mais complexas, atuando em redes organizadas e projetos cooperativos para o bem estar do planeta. (CORAL, 2002, p. 30). 
Além disso, o posicionamento da empresa no cenário mercadológico e também social afetam diretamente sua credibilidade. Coral (2012) novamente aponta sobre as estratégias relacionadas a questão socioambiental que:

\begin{abstract}
A análise e implementação de estratégias e ações relacionadas ao meio ambiente natural e ao fator social envolvem todos os setores de uma organização de forma multidisciplinar. Por isso, não podem ser tratadas como responsabilidade de apenas um departamento ou função organizacional. A forma como a empresa se posiciona afeta diretamente seus resultados, positiva ou negativamente. (CORAL, 2002, p. 80).
\end{abstract}

Destaca-se, portanto, que as ações de planejamento devem estar articuladas com todos os setores da organização, começando dos setores estratégicos para os demais, para que possam responder da melhor maneira ao processo de sustentabilidade, utilizando uma linguagem conexa. Os diferentes níveis de planejamento (estratégico, tático e operacional) devem estar alinhados aos conceitos da sustentabilidade (nas suas três esferas: ambiental, social e econômico), e a sustentabilidade deve estar presente em todos os níveis, conforme Figura 1.

Figura 1. Nível de Planejamento e Sustentabilidade
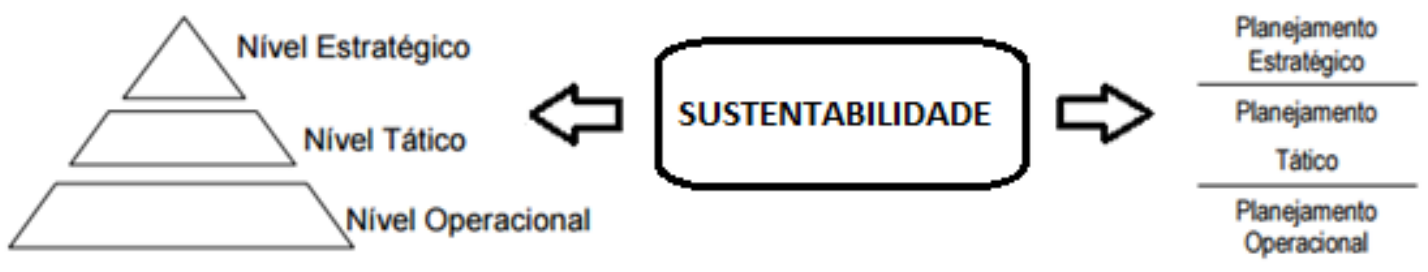

Fonte: Elaborado pelos autores (2015) adaptado de Oliveira (1997)

Enfatiza-se, então, que não somente no nível estratégico que a sustentabilidade deve fazer parte, mas em todos os níveis de tomada de decisão. Sendo assim, os conceitos de sustentabilidade inseridos no planejamento de uma organização eleva a possibilidade dos gestores e funcionários pensarem sob a ótica dos três pilares: social, econômico e ambiental, que de certa forma, contribuirá para o processo de sustentabilidade em duas frentes: a da própria organização no campo do agronegócio e da sociedade de forma ampla. 


\section{CONSIDERAÇÕES FINAIS}

Por meio desta revisão bibliográfica procurou-se analisar os principais aspectos que envolvem um planejamento estratégico, a partir da sua definição, do posicionamento na organização, até as possibilidades de sua aplicação. Posteriormente, foi apresentada uma conexão entre o planejamento estratégico e a sustentabilidade, com maior ênfase à área do agronegócio, dada sua representativa importância econômica.

Entende-se que o agronegócio afeta e é afetado local, regional, nacional e globalmente. Considerando-se que dele fazem parte organizações produtoras de gêneros alimentícios e "comodities", tudo proveniente do cultivo da terra pela ação antrópica, isso afeta diretamente o meio ambiente, além de envolver outros aspectos como empregabilidade, cultura e desenvolvimento econômico.

Diante disso, o planejamento estratégico demonstra ser uma importante ferramenta para a organização e para o processo de sustentabilidade na área do agronegócio, aqui incluindo-se tanto o pequeno como o grande produtor.

Para que ocorra o processo de sustentabilidade o planejamento estratégico deve incluir na sua elaboração os três pilares da sustentabilidade. Utilizou-se a definição de sustentabilidade formulada pela comissão de Brundtland 1987, modelo mais divulgado em escala mundial.

Nesse sentido, ao analisar o cenário de atuação da organização e projetar os planos para o futuro, os aspectos ambiental, social e econômico devem ser observados de maneira que estejam integrados. Como o planejamento remete a algo futuro, a longo prazo, e suas projeções baseadas em incertezas, ele pode ser articulado em conformidade com as bases da sustentabilidade, que visa o uso racional dos recursos e posterior desenvolvimento econômico e social para as presentes e futuras gerações.

Portanto, essa visão antecipada das projeções de incertezas futuras tratadas no planejamento estratégico pode auxiliar o desenvolvimento sustentável do agronegócio, sendo de grande utilidade a sua implantação.

Considere-se que este trabalho é uma contribuição para reflexão e futuras pesquisas que podem confirmar a importância do tema, bem como avançar em 
busca da implantação do planejamento estratégico à vista da sustentabilidade no agronegócio.

\section{REFERÊNCIAS BIBLIOGRÁFICAS}

BARBOSA, Emerson Rodrigues; BRONDANI, Gilberto. Planejamento Estratégico Organizacional. Revista Eletrônica de Contabilidade - Curso de Ciências Contábeis, UFSM. V. 1, n. 2, dez/2004fev/2005.

BAUMAN, Z. O mal-estar da pós-modernidade. Rio de Janeiro: Jorge Zahar, 1998.

CANTELLE, T.D. et al. Competitividade na Agricultura Comercial versus Sustentabilidade Ambiental. Revista em Agronegócio e Meio Ambiente, Maringá, v. 6, n. 1, p. 171-188, Jan 2013.

CLARO, P.B.D.O.; CLARO, D.P. Sustentabilidade estratégica: existe retorno no longo prazo? Revista de Administração, Sao Paulo, v. 49, n. 2, p. 291-306, Apr 2014.

CORAL, Eliza. Modelo de Planejamento Estratégico para a Sustentabilidade Empresarial. Tese de Doutorado, Programa de Pós Graduação em Engenharia de Produção, Universidade Federal de Santa Catarina. Florianópolis, 2002.

FERNANDES, Ana Cláudia Terence. Planejamento estratégico como ferramenta de competitividade na pequena empresa: desenvolvimento e avaliação de um roteiro prático para o processo de elaboração do planejamento. 2002. Dissertação (Mestrado em Engenharia da Produção) - Escola de Engenharia de São Carlos, Universidade de São Paulo. São Paulo, 2002.

GIL, Antonio Carlos. Métodos e Técnicas de Pesquisa Social. 6 ed. São Paulo: Atlas, 2014

GUIA DO EMPRESÁRIO. Disponível em <http://www.guiaempresario.com/custo-da-mao-de-obra-nobrasil/ > Acesso em 30 mai 2015

HALL, Stuart. A identidade cultural na pós-modernidade. 11 ed. DP\&A Editora: Rio de Janeiro, 2006.

MAZZA, V.M.D.S. et al. Gestão de Resíduos Sólidos em Propriedades Rurais de Municípios do Interior do Estado do Rio Grande do Sul. Revista em Agronegócio e Meio Ambiente, Maringá, v. 7, n. 3, p. 683-706, Sep 2014.

MARCONI, Marina de Andrade; LAKATOS, Eva Maria. Técnicas de Pesquisa. 7 ed. São Paulo: Atlas, 2010

MEDEIROS, João Bosco. Redação Científica - A prática de fichamentos, resumos, resenhas. 11 ed. São Paulo: Atlas, 2012

MOTTA, Paulo Roberto. Dimensões Gerenciais do Planejamento Organizacional Estratégico. $R$. Adm. públ .. Rio de Janeiro, 10(2):85-107, abr./jun. 1976

OLIVEIRA, D. P. R. Planejamento estratégico: conceitos, metodologia e práticas. 11 ed. São Paulo: Atlas, 1997.

PEREIRA JUNIOR, Humberto dos Santos et al. Materials Management: a reverse logistics case of agrotoxics empty containers in a sugar and alcohol company. European Scientific Journal. September, 2013 edition. v.9, n. 26 
SILVA, Devanildo Braz da; PEREIRA, Marlos da Silva; SPROESSER, Renato Luiz. O Planejamento estratégico como ferramenta para obter vantagem competitiva no agronegócio. Anais do Encontro Científico de Administração, Economia e Contabilidade, v. 1, n. 1, 2011. 